\title{
Rural Cultural Research: Notes from a Small Country Town
}

\section{Kate Bowles}

Wollongong has sophistication of a large city yet the charm and welcome of a small country town [sic].

(Tourism Wollongong, February 2008)

I live in Wollongong. All I can say is this is a typical Wollongong situation. The city is like a small country town and highly incestuous, especially with long term residents, property owners and business connections.

$$
\text { ('Margaret, Wollongong'; reader response to Larter) }
$$

'Wollongong is like a small country town. A lot of people know each other,' was Mr Gilbert's explanation. (Wollongong is NSW's third largest city with a population approaching 200,000)

(Frew)

What kind of denial does it take to look at a major industrial city in the midst of a crisis of self-reinvention involving millions of dollars of urban infrastructure, and see only a small country town going about its business as usual? And how does this relate to the strategic marketing of an urbanised coastal tourist destination that downplays the amenities of urban life in favour of the intangible qualities of small town experience? Whatever its literal dimensions in terms of population or location, the imagined small country town functions - in Australian media and other public discourse - in multiple ways. The country town image is, on one hand, easily dismissed and criticised and, on the other hand, a source of comfort and reassurance. A relatively stable image of the country town continues to make a curious kind of sense, at least in terms of seemingly persistent national myths and ideals. 'Come on,' such an image seems to proclaim, 'we're all Australians, we know what country life is about'. Of course, most Australians don't have direct experience of small country towns. Rather, they have a perverse familiarity with popular Australian television serials and movies - from Bellbird to $A$ Bed of Roses, as well as imaginary communities from Mt Thomas to Summer Bay (see Botterill) - and how they promote images of 'rural' or regional life in a national context. It's this familiarity with a set of ideas about rural charm and hospitality that makes media promotion of Wollongong as a small country town 
an ideal means of attracting tourists. At the same time, less desirable associations - such as parochialism or a town's insignificant profile on the national scene - can be called on to minimise the State political implications of a local corruption investigation. ${ }^{1}$ This is only a small country town, after all: charming, harmless and easily misunderstood by outsiders.

In what follows, I want to suggest that the pragmatic use of the image of Wollongong as a small country town in media and tourist promotions has some interesting implications for those of us who research actual small country towns in Australia. I also want to propose that despite its potentially modest national benefit, small country town research is important to Australia precisely because of the political utility of the stereotype. The image of the small country town combines practical assumptions about size, location and isolation, but any or all of these may be missing in the definition of a given town as small and rural in character, as the Wollongong case most strikingly demonstrates. ${ }^{2}$ It's the persistence of these contradictory reputations - the charm and the parochialism - that should prompt rural cultural researchers to offset the stereotypes with alternative stories about the diversity of contemporary cultural experiences as collected in their encounters with everyday life in small country towns. Such encounters might include the experience of not being welcomed, or of not knowing anyone, let alone everyone - experiences that are part of the changing realities of country towns in which there has been significant in-migration of diverse social groups (from resettled refugee communities to urban treechangers in flight from mortgage stress). Some small country towns have flourished as hubs of regional social mobility, as their natural amenities attract new populations. New educational and employment opportunities begin to flourish, enabling young people to stay. On the other hand, some country towns have struggled to achieve the necessary conditions for either economic or cultural sustainability, and are now dealing with the challenge of supporting an ageing population who cannot afford to leave.

There is therefore no convincing single model of a small Australian country town, nor should it be the mission of rural cultural research to flush one out. Rather, there is an opportunity for rural cultural research to engage with one of Australia's keynote stories of national identity by exposing and exploring the diversity of lifestyles and cultural amenities as well as new pressures and alliances which constitute country town life. This is also an opportunity for cultural researchers to become involved in forms of community engagement that

\footnotetext{
${ }^{1}$ In February 2008, the New South Wales Independent Commission Against Corruption's 'Public Inquiry Into Allegations of Corrupt Conduct Concerning Wollongong City Council' was the subject of extensive national media coverage and talkback discussion.

2 According to the ABS Yearbook 2007, the population of Wollongong is now around 276,000, and the city is the ninth largest in Australia. I am grateful to Andrew Gorman-Murray for drawing this to my attention.
} 
can enhance the existing regional aspirations of our tertiary institutions. Indeed, 'community engagement' has become an important policy emphasis in the university sector, as shorthand for the complex ideals of public good and social wellbeing that substantiate the sector's claim on government funding. This in turn has brought about the renovation of a term which seems recently to have slipped from view: praxis. The idea of praxis explicitly connects theoretically informed research to pragmatic modes of cultural learning. It is a style of research that is attentive to the principles of mutuality and participation between researchers and members of the wider community, grounded in respect and perhaps even institutional humility. In the context of rural cultural research, it challenges both metropolitan and non-metropolitan-based institutions to make a reflective and practical contribution to ways in which small country towns can respond to the changes that confront them.

In proposing that rural cultural research - as a mode of engagement with regional communities - might be a useful focus for some disciplines within the humanities, I certainly do not mean to suggest that rural cultural research has been ignored in Australia until now. What interests me is not how much research has been done, but how little communication there has been among researchers with shared interests and shared practical experiences. The explanation for this, I think, lies in the necessarily diverse disciplinary definitions of culture that frame such research, that can make it difficult to find and collate examples of rural cultural research when it is spread across an array of different, often disconnected, journals and publications. Most rural research is produced from the perspective of a single discipline. In Australia, as elsewhere, the assumption has been that the study of rural experience lies within the jurisdiction of the social sciences; and that rural cultural research, more specifically, is a form of anthropology. Sociologists, geographers, political scientists and economists have certainly taken rural life seriously, to the extent that rural sociology is a field in its own right; and in so doing they have often taken cultural institutions and their constituents into account. Cultural geographers have been particularly sensitive to the ways in which interpretations of place, belonging and community intersect with questions of identity and rural cultural practice (Waitt and Gorman-Murray). Meanwhile, literary and film scholars have explored common themes in the representation of Australian rural life. Historians have studied the persistence of these same themes in the institutions of public life which through the nineteenth and twentieth centuries preserved the image of Australia as an agrarian culture, rather than simply an agrarian economy (e.g., Waterhouse). Disciplines with a strong historical focus, including literary studies, have consistently drawn attention to the rhetorical significance of a rural/urban divide in constructing Australian national identity, and this has certainly informed some analysis of Australian films and even television series. 
But those disciplines centrally concerned with the production and consumption of contemporary culture - cultural studies, communication studies, creative industries research and media studies - have so far been less interested in moving beyond analysing images of rurality to a more systematic approach to the forms of everyday cultural practice and experience which matter in rural, regional and remote communities. There are important exceptions to this, of course (see Dwyer; Gibson and Robinson; Goggin; Tacchi; and van Vuuren). And there are also valid institutional reasons for the comparatively low profile of rural research in these disciplines, particularly given their core interest in the cultural impact of media forms which are still relatively difficult to access in many country areas. It can be difficult enough to keep up with the cultural impact of new media industries, practices, policy and legislation, without having to track the disconcerting effects of these on the other side of the digital dividing range. Add to this the existing community commitments of the major cultural research centres, most of which are themselves located in metropolitan or outer-metropolitan areas, as are their primary funding partners, and the practical impediments to sustained analysis of media and cultural institutions and practices in small country towns are clear.

It may also be that the convincing case for this kind of cultural research has yet to be made. Media and cultural studies scholars perhaps have less of an investment in reappraising the Australian legend, or its political expression in 'countrymindedness' (Aitken; Botterill), than other humanities scholars. Whereas other national traditions in cultural studies generated by the work of Raymond Williams, Richard Hoggart and E.P. Thompson have championed rural working class culture, even in a limited way, as part of a larger political engagement with the ordinariness of culture, in Australia it has been harder to define rural culture as politically progressive. Australian cultural studies has functioned as a significant enabling site for the exploration of identities formed in opposition to the dominant national culture, and it is still too easy to think of this dominant culture in terms of images which have their origins in colonial white pastoralism. It may be that the lingering spectre of rural social conservatism-however fair or unfair this stereotype may be - still limits the opportunity to engage critically with the present-day cultural experiences of rural Australians. But there is a more sympathetic view which we can take of the national deficit in rural cultural research, which is that the current structure of our research institutions, and the everyday realities of our lives as researchers working mostly in cities, makes rural cultural research genuinely challenging to undertake.

I make this observation having spent five years pursuing research in the south coast town of Bega and its outlying villages. Bega is a small regional town, at the centre of dairying and timber industries, which has also begun to experience the effects of statewide population mobility as treechangers and seachangers move into the network of smaller towns and villages in the surrounding Local 
Government Area, as well as into Bega itself. It is closer to the Victorian border than it is to Sydney, and there is no rail link, making road and shipping traffic critical to its communications and transport history. I came to research in this region as a result of teaching into an Arts degree offered in Bega by the University of Wollongong. From the community of staff and students involved in this program, I learned about the region and its sensitivities, its contested and cherished histories, its international linkages both longstanding and recent, ${ }^{3}$ and its current social issues (see also McKenna). An accidental part of my introduction to some of the key regional media and communications concerns involved simply driving between Wollongong and Bega many times, staying in many motels, experiencing local internet access, and watching local television ads. Further encouraged by informal research already undertaken by students we had worked with, my colleague Nancy Huggett and I prepared to investigate the popular memory of cinema-going in the early twentieth century in Bega and its surrounding villages.

Cinema studies is a particularly problematic discipline for rural research, however, as there is still so little tolerance within its major journals and conferences for research into cinema distribution and exhibition that it is even more difficult to make a case for rural research which explicitly challenges the dominant association of cinema-going with specifically urban modernity (see Matthews). The significance of an Australian picture show operating in a local hall in a village with a population of less than 400, for example, is difficult to promote in terms of its importance to world cinema history. Nevertheless, it is critical not to let the history of cinema's carriage of modern life be modelled only on urban and suburban cultural experiences, as this ignores the fact that for much of cinema's supposed heyday of regular weekly movie attendance, both in Australia as well as the major markets in the USA and Europe, the experience of movie-going was far more diverse, and for many, far less glamorous than that suggested by the typical representation of the metropolitan picture palace.

Our research provides ways of critiquing some of the assumptions inherent in research about cinema audiences in the pre-television era. In particular, it became clear that in rural villages where a single picture show was the norm, there were other reasons for going to the pictures than to escape into the imaginary social world referenced by the glamorous Hollywood movies on screen. In fact, the quality of the film print was sometimes quite poor after its long journey by rail and road around the country exhibition circuit, and in some villages there was evidently the risk that in bad weather the film might not show up at all. There was so little choice, that the movie itself couldn't be seen as the primary motivator

\footnotetext{
3 The Bega-Littleton (USA) international citizens' exchange program is one of the oldest in Australia, for example, having commenced in 1961.
} 
for the occasion. The venue was likely to be basic, often either very cold or very hot, the bench seating was sure to be uncomfortable, and there was little to do during frequent breaks in projection other than duck out for a smoke, or nip down the road to the pie shop. But the social experience of getting together with other members of the community, particularly for women and children who were not in the pub, was a critical element in sustaining modest rural picture shows operating under very marginal conditions. Picture show licensees were also often prominent community figures, either through their association with social clubs and committees, with local newspapers, or with other town businesses. Despite the limited respectability of the movie business when compared with the country press, the Show Committee or the Lodge, these cultural entrepreneurs were often very successful in tapping into the notion of community loyalty and suggesting that patronage of the pictures was part of a larger project to advance the commercial prospects of one village over another.

Memories of rural cinema-goers also suggested to us that a town's isolation from metropolitan centres was a contributing factor in how cinema goers experienced the cinema. This challenges other accounts that have focused, more generally, on rivalry between cinema and the early television industry. City-based media operators have been important to the delivery of new media, whether as transporters of film cans around rural roads in the 1930s, as broadcasters of television signals into rural valleys in the 1960s, or as promoters of digital mobile phone access in country areas in 2008. In our case, we found that the discourses of small town mutuality and economic resilience that had sustained the early cinema industry were equally available to the first entrepreneurs who set about furnishing rural households with television sets or arranging for the installation of aerials at a time when achieving reception could be quite hit and miss. In each case, the late arrival or patchy quality of a new media form signalled the resumption of a familiar local conversation, particularly in letters to the press, about rural service entitlement. What does it mean to be contributing via the electoral and taxation systems to the regulation and distribution of something of national importance, while at the same time being excluded from it by reason of geography? In practical terms, what does it mean repeatedly to read or hear about something which is reputed to be transforming everyday domestic life in profound ways, but which you have little prospect of accessing in your own home? Our research leads us to propose that the conventional single-medium approach to histories of radio, cinema or television does not function well in analysing the distinctive ecologies of media use in rural places, where the rise and fall of particular media might have as much to do with weather or topography as with content (see Bowles).

Glossed in this way, the project seems to have sailed smoothly, with the rapid paddling of the research effort almost entirely concealed beneath the untroubled surface of research outcomes. But in sharing our experiences with others, we 
have come to feel that it is important to highlight the critical social and community relationships that constituted the research experience itself, and to think about the possibility that some aspects of this interdependency might be particular to rural research. Again, it is not my intention to suggest that rural cultural research is special, but I want to stress that the ways these issues are overcome provides important opportunities for university-based cultural research to consolidate its reputation for imaginative and politically committed participation in community development. In particular, we can start to appreciate that intimate microhistorical studies of culture matter very much in local contexts, not because they generalise across the nation (of course they don't) but precisely because they retain traces of the discourses which continue to frame local cultural opportunities or exclusions.

There are, however, three key practical challenges which frame the rural research experience: the nature and location of source materials; the need to work across institutions; and the potential gap which may exist between community expectations and university research agendas, outcomes and timeframes. In the first place, most rural cultural fieldwork is carried out at some distance from the relevant archival collections, which are commonly in metropolitan libraries and institutions. This is a problem compounded by the lack of digital access to country press archives, and the sometimes poor condition of older microfilm readers in local libraries. Archival materials which are held locally are often in private hands or have been lodged with unfunded historical and genealogical societies, and for this reason they are rarely indexed beyond the capacity of heroic volunteer efforts to keep them safe in folders or photograph albums. Even to photocopy a document or record book held in someone's home means gaining permission to take it away. There is no funding for digitisation, and very little capacity to undertake the collection or transcription of oral histories. For understandable reasons, many local historical societies have focused on histories of work and schooling, of prominent families, or of contributions to war. Neither these nor the heritage studies of landmark local buildings will necessarily have provided a logic for collecting the history of media consumption. Information about local cinema, radio and television - if it has been collected at all - is often filed away with race meetings, balls, and cricket matches. In our search for what little has been collected on cinema history in the far south coast, we have often relied on the superb recollection of individual volunteer staff at the Bega Historical Society as to the possible location of relevant documents.

This relates to the second practical challenge: linkages with such marginalised collecting institutions are less attractive to universities looking to maximise research income - again, for obvious and understandable reasons - than are partnerships with State museums and archives. While these small local institutions are often most in need of research assistance, and universities are surely most able to supply it, these are not financially lucrative contracts, and 
the prospects of generating commercial or even conventional academic research outcomes are unpromising. Rural cultural research, particularly with a historical focus, is therefore probably best undertaken by sharing some of the resource implications across metropolitan institutions, both in the higher education sector and with funded collecting institutions. This creation of multilocational joint ventures, however, has the capacity to lead to complex project management issues, compounded by the likelihood that researchers from more than one metropolitan institution are now trying to juggle schedules in order to travel together to a remote location.

The third challenge is in some ways the most interesting. Rural cultural research is heavily dependent on the support and participation of local researchers, many of whom work in a voluntary capacity. Are we sufficiently attentive to their motivation for supporting the research, and conscientious in ensuring that our research outcomes also meet their needs? In our research, for example, we have relied on museum volunteers to remember where a document might have been filed, and their network of local contacts has been our key introduction to the older members of the community who recall the period we are researching. They have also directly facilitated what we have learned as we have travelled around the district, or spent afternoons in the museum. On many of our interview trips we have been accompanied by a museum volunteer whose local social knowledge has combined with an active and well-informed interest in our project to enhance our interview conversations. Where we have failed to pick up on a particular name or reference in a fast moving exchange, our museum colleague has gently and tactfully intervened with a question of her own, the value of which we have later appreciated when transcribing the interview and reflecting on the turns taken in the conversation.

Of course, none of this is exclusive to rural cultural research. Most qualitative research experiences contain a dimension of gratitude to the combined operation of chance and the kindness of strangers; or on the other hand a dimension of awkwardness at the sometimes compromising nature of hospitality (see Huggett). But in any situation where the institutional status of the researcher and the researched is unaligned, or there is good pre-existing reason for mutual suspicion or misunderstanding, these are more than incidental elements. In rural towns, sustained cultural research which is locally credible depends on the gracious and supportive curiosity of those who have made a longstanding commitment to the curation of their own histories. Our reliance on their kindness and perceptiveness takes us into the realm of the difficult gift, described very movingly by Ethiopian scholar Teshome Gabriel in his account of his return from Los Angeles to his mother's home in Africa. His mother's unexpected composure, and the generosity with which her community instate him as a respected elder, cause him to reflect on their gift to him of insights which emerge 
from their lived experience, which is 'intolerable' precisely because he can never return it.

It is this gift that has often been forgotten, as I myself forgot it, thinking that I could stand outside it, recording and analysing it from a critical distance.

If we acknowledge the gift, will it be less of a gift? Not really. Because the gift is just like an heirloom - it is to be forwarded, to be passed on to the next generation. Or to put it metaphorically, one can join the ends of a braided rope only by overlapping its strands. The gift, then, is not a state of being: it is continually enacted, lived and performed. (83)

This has been a critical reflection for us, as it has also been our experience that the performativity of the conversational gifts that have been shared with us is continually enacted in the ways in which we handle these gifts and pass them on. This places upon us a degree of ethical responsibility which overflows the strict requirements of university ethics clearance - a practice which itself often appears as a self-protective expression of institutional risk management. ${ }^{4}$ As all researchers know, compliance with human research protocols is no guarantee against later carelessness in the way that transcribed conversations are selectively quoted, interpreted, summarised or dismissed. Discourteous or self-serving uses of the gift of shared time and ideas sometimes occur simply through misunderstanding and lack of time to reflect. However, rural fieldwork can make it particularly difficult to return promptly for a second conversation, to consult further to check whether or not an inference was correctly understood or a story heard in the spirit in which it was told. The conflict between the need to linger over the careful management of personal memories and ideas and the need to hurry on to the analysis of results is set up by the conventional assumptions of research efficiency, and particularly by the normal timeframes of funded research projects, which produce such a chastened sense of the value of extended consultation and reflection. Under these circumstances, the distorting and distracting impact of the national research economy and its accounting practices create for many academics a very significant disincentive to what we might call slow research. Yet for many reasons, slow research may be the most appropriate means of building effective participatory research partnerships between researchers located in cities and their community co-researchers in rural towns.

\footnotetext{
4 Jonathan Rutherford, citing Michel Callon, suggests that cultural studies itself should seek to return to the overflow which is created by the impossibility of framing all externalities - all 'actors and their relations' - within a market. 'The human attribute of the desire to know, [sic] finds itself displaced and marginalised by the market imperatives of the corporate university. But like Derrida's idea of the supplement, it marks what this kind of university lacks but also what it needs to confirm its identity' (314).
} 
In Australian cultural research, slow research faces a separate challenge, again from an emphasis which is understandable and productive in its own context. The cultural research disciplines have made a clear commitment to achieving meaningful dialogue with government and industry, and it has to be said that slow research is hardly the attribute to promote in seeking consultancy outcomes or policy interventions. The strategic priorities of timeliness and productivity measures find their expression in a dominant institutional culture which considers projects successful precisely because they have ended-a measure of success which has some limitations if the goal is to create healthy long-term collaborative relationships beyond the immediate grant life-cycle. It is in part this short-term and self-interested nature of the university funding system that can undermine opportunities to build trust between universities and their research constituencies and can make some of the long-standing sensitivities of rural cultural research-particularly those involving non-indigenous researchers and Indigenous cultural knowledge-very difficult to resolve. Combine the underpinning assumptions of research productivity with the challenge of sharing research income across disciplines and across the university sector, and the cumulative result of all of these pressures, each slight but trying in its own way, is severe institutional constraints on finding imaginative ways to engage with rural communities.

These essentially bureaucratic constraints come into sharp focus within intellectual debates taking place in cultural research disciplines, particularly those concerning the utility of theory and the normative assumptions which may have been made in the past about ordinary culture being exemplary when framed within the lived experience of the first world metropolis and its suburbs. In Australia, many cultural researchers have tackled the entrenched local bias against taking suburban life seriously, but this has not naturally generated a move towards places further beyond the margins of the metropolis. Catherine Walsh writes persuasively that these assumptions perpetuate the experience of subalternity in situations where cultural research and critical pedagogy are being deployed in practical attempts to build opportunities for local social change. Reflecting on the development of a doctoral program in Latin American Cultural Studies in Quito, for example, she suggests that the purpose of initiatives like this isn't simply to expand the market for western cultural studies, but to re-engineer its longstanding theoretical preoccupations in ways that are more likely to create locally relevant outcomes.

The effort is conceived as a space of encounter between disciplines and intellectual, political, and ethical projects, projects constructed in different historical moments and epistemological places and concerned with the search for ways to think, know, and act towards a more socially just world and towards the comprehension and change of structures of 
domination-epistemological as well as social, cultural and political.

African scholars have put forward a similar critique of the generalising tendency in western theories of popular culture (see in particular Tomaselli; Tomaselli and Wright; and Wright and Maton), with a similar focus on community engagement as a form of critical pedagogy. Keyan Tomaselli, for example, offers a rich account of the practical difficulties of taking a group of students to conduct fieldwork in Botswana as a means of illustrating his dissatisfaction with international cultural studies. Cultural studies, he argues, has become preoccupied with its own celebrity, and has stalled in its discussion of the ways in which popular media can be thought about, continuing to position it in theoretical terms which normalise the western urban experience. Like Gabriel, Tomaselli writes about the cultural and economic impact of his presence among communities with whom he works. He suggests that this places ethical expectations on him to respect their relative situations, and to remain mindful of his own limitations.

How can power relationships be negotiated to the benefit of all parties to the encounter? This is one of many difficult, uneasy, and unclear questions we kept asking ourselves. Perhaps cultural studies scholars should ask them more often than they do. (313)

As I suggested earlier, if we were to ask Tomaselli's question in the context of research into small country towns in Australia, one answer would be that the renegotiation of power can be the means to a re-awakened sense of praxis - a reflective, committed engagement to learning about rural culture in partnership with small town communities and in response to their interests, rather than a selective and short-term recruitment of their cultural knowledge to meet our needs. Handel Kashope Wright suggests that commitment to praxis requires us to be exceptionally mindful of our own autobiographies as research professionals (810), not in order to claim the extra privilege of authenticity but rather to destabilise that part of our identity underwritten by conventional demonstrations of rigour and objectivity, and in so doing to rebalance the partnership between the researcher and the researched (817-8).

In practice, this attentiveness to the character of our relationship to our collaborating research partners, whatever their institutional status, asks us to do four things. Firstly, it requires us to continue working very closely, and sometimes very slowly, with community stakeholders to recognise the existing capacity for rural cultural research in unfunded institutions, volunteer groups and the learning communities which are being developed by ICT networks such as the NSW Community Technology Centres funded under the auspices of Networking the Nation in 2000 (see van Vuuren for a discussion of the objectives of the rural telecentre initiatives enabled by this funding program). Secondly, it entails the sharing of research productivity, particularly in terms of 
contributing to local museum displays, promotional activities, small-circulation pamphlets and monographs, or collections of oral histories, which are meaningful to small communities but might not stack up as measurable outcomes in terms of the crude point-driven economy of academic productivity. Thirdly, it suggests that we view rural cultural research as an opportunity to build capacity in the university sector by taking a more open-minded (and open-ended) approach to using digital repositories to share original fieldwork data across institutions, rather than simply publishing that sliver of our fieldwork which typically appears in a conference paper or journal article. This is a critical challenge to oral historians and those of us working with life narratives, as it requires us to think at an early stage in the research design of the potential which transcribed conversations have to be shared with researchers on other projects, in other institutions - for which the appropriate level of permission must be planned from the start.

Finally, we have reached a point when the definition of 'rural', from the perspective of the even more slippery 'cultural', needs refreshing. On the one hand, an entrenched and outdated image of the pastoral sustains a number of urban fantasies and fears, from the faux corrugated iron panels cladding inner city renovations, to gourmet farmers' markets, and ultimately to the idea that a city the size of Wollongong can be thought of as a small country town. The image of the resilient, apple-cheeked and unsophisticated Australian way of life is also relentlessly deployed in the marketing of Australia at home and abroad. But the realities of the networked nation have changed some aspects of cultural life in small country towns in ways that suggest a radical break with the mid-1980s emphasis on 'countrymindedness'. Young media users in country towns are now part of national and global social networks, rather than confined to the subcultures that happen to exist in town; previously isolated rural parents can seek advice and community over the internet; and traditional business owners or even self-employed treechanging cultural workers are able to meet their clients and pay their bills flexibly from a wider range of different locations. There are still very significant limitations and disruptions to the standard of media services in non-metropolitan places, but it is nevertheless the case that the horizon of social relations and cultural experiences in small country towns has changed. This calls for a change to the way in which we approach rural cultural research, and it calls for more effective participatory research partnerships, so that the agenda for this research is calibrated to the extensive cultural knowledge which already exists in the community.

Keyan Tomaselli likens cultural studies to a 4WD which is engineered for tough off-road conditions but never leaves the suburbs (311). This has some resonance for those of us concerned that the cultural research disciplines can look like a fleet of metropolitan hire cars available for the occasional return trip to the country - vehicles which proclaim when parked at farms and on country town 
streets that the drivers are passing through, and 'not from around here'. But by asking the difficult questions about institutional power, and engaging in a more direct way with the research expertise outside the academy, we can begin to adopt more sensitive and sustainable practices. The payoff for this should be that we succeed in linking the agenda for Australian rural cultural research both to the longstanding intellectual commitments we have to praxis, as well as to more recent institutional investments in regional community engagement.

Kate Bowles is a Senior Lecturer in Media and Cultural Studies at the University of Wollongong, researching the social and cultural history of cinema-going in rural New South Wales. With researchers at Flinders University, RMIT and the ANU she is working on a large scale database of Australian cinemas and related distribution companies, and the integration of GIS mapping into media historiography.

\section{Works Cited}

Aitken, Don. "'Countrymindedness": The Spread of an Idea.' Australian Cultural History 4 (1985): 34-40.

Botterill, Linda. 'Soap Operas, Cenotaphs and Sacred Cows: Countrymindedness and Rural Policy Debate in Australia.' Public Policy 1.1 (2006): 23-36.

Bowles, Kate. "'All the Evidence is that Cobargo is Slipping": An Ecological Approach to Rural Cinema-Going.' Film Studies 10 (2007): 87-96.

Dwyer, Tim. 'Recalibrating Policies for Localism in Australia's Commercially Networked TV Industry.' Media International Australia Incorporating Culture and Policy 108 (2003): 125-144.

Frew, Wendy. 'Planner aware of colleague's dates with developer.' Sydney Morning Herald, 25 February 2008. http://www.smh.com.au/news/ national/i-knew-morgan-and-vellar-were-having-dates/2008/02/25/ 1203788210047.html

Gabriel, Teshome H. 'The Intolerable Gift: Residue and Traces of a Journey.' Home, Exile, Homeland: Film, Media, and the Politics of Place. Ed. Hamid Naficy. New York: Routledge, 1999. 75-83.

Gibson, Chris and Daniel Robinson. 'Creative Networks in Regional Australia.' Media International Australia Incorporating Culture and Policy 112 (2004): 83-100.

Goggin, Gerard. 'Rural Lines of Flight: Telecommunications and Post-Metro Dreaming.' Transformations 2 March 2002 $<$ http://www.transformationsjournal.org/journal/issue_02/pdf/goggin.pdf>. 
Huggett, Nancy. "“Everyone was Watching!" Strategies of Self-Presentation in Oral Histories of Cinema-Going.' Studies in Australasian Cinema 1.1 (2007): 261-274.

Larter, Paul. 'Beth Morgan is the woman behind the "mile high rise club".' Times Online, 23 February 2008. http://www.timesonline.co.uk/tol/news/ world/article3420017.ece.

Matthews, Jill Julius. Dance Hall and Picture Palace: Sydney's Romance with Modernity. Sydney: Currency Press, 2005.

McKenna, Mark. Looking for Blackfellas' Point: An Australian History of Place. Sydney: UNSW Press, 2002.

Rutherford, Jonathan. 'Cultural Studies in the Corporate University.' Cultural Studies 19.3 (2005): 297-317.

Tacchi, Jo. 'Researching Creative Applications of New Information and Communication Technologies.' International Journal of Cultural Studies 7.1 (2004): 91-103.

Tomaselli, Keyan G. 'Blue is Hot, Red is Cold: Doing Reverse Cultural Studies in Africa.' Cultural Studies <=> Critical Methodologies 1.3 (2001): 283-318.

—. and Handel K. Wright. 'Editorial Statement: African Cultural Studies.' Cultural Studies 22.2 (2008): 173-186.

Tourism Wollongong. <http://www.tourismwollongong.com.au/conference/ default.asp $>$ accessed 25 Feb 2008.

Van Vuuren, Kitty. 'Understanding "Community" in ICTs and Community Broadcasting: Some Similarities and Differences.' Media International Australia Incorporating Culture and Policy 118 (2006): 120-135.

Waitt, Gordon and Andrew Gorman-Murray. 'Homemaking and Mature Age Gay Men “Down-Under": Paradox, Intimacy, Subjectivities, Spatialities and Scale.' Gender, Place and Culture: A Journal of Feminist Geography 14.5 (2007): 551-569.

Walsh, Catherine. 'Shifting the Geopolitics of Critical Knowledge.' Cultural Studies 21.2 (2007): 224-329.

Waterhouse, Richard. The Vision Splendid: A Social and Cultural History of Rural Australia. Fremantle: Curtin University Books/Fremantle Arts Centre Press, 2005

Wright, Handel K. 'Cultural Studies as Praxis: (Making) an Autobiographical Case.' Cultural Studies 17.6 (2003): 805-822.

—. and Karl Maton 'Cultural Studies and Education: From Birmingham Origin to Global Presence.' Review of Education, Pedagogy and Cultural Studies 26.2 (2004): 73-89. 